International Journal of Library \& Information Science (IJLIS)

Volume 7, Issue 1, January-February 2018, pp. 7-12, Article ID: IJLIS_07_01_002

Available online at

http://iaeme.com/Home/issue/IJLIS?Volume=7\&Issue=1

Journal Impact Factor (2016): 8.2651 (Calculated by GISI) www.jifactor.com

ISSN Print: 2277-3533 and ISSN Online: 2277-3584

\title{
SELF-EFFICACY TO USE ELECTRONIC INFORMATION RESOURCES. A STUDY ON THE USERS OF RESEARCH INSTITUTES OF PUNJAB
}

\author{
Gurjeet Kaur Uppal \\ Department of Library and Information science, Gulbarga University, Kalburagi
}

\begin{abstract}
:
The major change in the way library stores and maintains knowledge came with the advent of computers and new technologies. Further, origin of Internet and the development of World Wide Web (WWW) have opened up new vista for communication of scholarly information and helping Libraries to create and maintain information through Libraries' Websites, Blogs to its users. As a result, more institutions are equipped themselves with new technology and their employees are challenged to be advanced with new technologies to complete their tasks. However, employees are sometimes express less enthusiastic response to adopt new technologies, even if it may helpful to complete their tasks. At this stage, Self-efficacy plays important role in mediating the impact of computer anxiety on the use of computer and related technologies. Present study covers three aspects i.e. computer anxiety, self-efficacy and ease of use of resources.
\end{abstract}

Keywords: Electronic information resources, computer anxiety, self-efficacy, research institutes, Punjab

Cite this Article: Gurjeet Kaur Uppal, Self-efficacy to Use Electronic Information Resources. A study on the Users of Research Institutes of Punjab, International Journal of Library \& Information Science, 7(1), 2018, pp. 7-12.

http://iaeme.com/Home/issue/IJLIS?Volume=7\&Issue=1

\section{INTRODUCTION}

With the advent of new technology, a lot of changes have occurred in human life. These changes in technology and in computer applications have led many research institutions and their employees to relay on the using of the new technology as a main media to complete their professional tasks. As technology is growing, it is difficult to imagine a task that should be completed without computers and advanced technology. As a result, more institutions are equipped themselves with new technology and their employees are challenged to be advanced with new technologies to complete their tasks. However, employees are sometimes express less enthusiastic response to adopt new technologies, even if it may helpful to complete their 
tasks. The acceptance and use of computer and related technologies by employees appear to be limited due to the fear of low confidence, low ability to use and perceived difficulty to use. However, many previous studies indicates that employees of the reputed institutions still having many issues dealing with computer and advance technologies. These existing studies indicated that employees interacting with new technologies experience a situation that is known computer anxiety or techno-stress.

\section{Computer anxiety}

Anxiety refers to a complex combination of negative emotional responses that include worry, fear, apprehension and agitation (saade.,kira 2009). it is a natural and unavoidable reaction to a perception of danger or risk.

Sometimes, technology has unpleasant side effects, which may include strong, negative emotional states that arise not only during interaction but even before, when the idea of having to interact with the computer begins (Saade.,Kira 2009). Anxiety, confusion, anger and frustration can affect not only the interaction with technology but also with usability and productivity etc. A person with computer anxiety may experience fear of using computers, feeling of frustrations, feeling difficult to find information, disappointment to find relevant information etc. therefore, he starts avoiding using technologies. Thus his performance might be poorer than those with little or no computer anxiety.

Therefore, it is necessary that certain steps must be taken to reduce the computers and related technologies' anxiety among employees and small steps must be taken to tackle employee's self-confidence.

\section{Self- efficacy}

Self-efficacy plays important role in mediating the impact of computer anxiety on the use of computer and related technologies (Achim., Kassim 2015). Self-efficacy is refer as Knowledge and ability to use computer and related technology. Individuals must feel confident and competent in using technologies and skills, in order to employ them effectively. According to Bandura (1977), learning certain skills is not enough, individuals should also develop confidence in the skills that they are learning. In other words, success is not simply based on the possession of necessary skills for performance, it also requires the confidence to use these skills effectively. This leads to self-efficacy. Bandura (1986) defines self-efficacy as a belief that one has about the capability to perform a particular behavior. According to Compeau and Higgins (1995), computer self-efficacy represents an individual's perceptions of his/her ability to use computer in the accomplishment of the task. Self-efficacy is important, because people tend to avoid tasks and situations which they believe exceed their capabilities, but nevertheless they undertake and perform activities they judge themselves capable of handling (Bandura,1986).

The above facts make it clear that self-efficacy leads to higher usage of computermediated technologies. Therefore, keeping in view the above facts, the present study makes an attempt to elicit the opinion of the respondents regarding the need for self-efficacy in using e-resources, since self-efficacy helps in exploiting the computers to meet their maximum information needs. This leads to a positive attitude towards computer mediated technologies and to satisfaction and finally to maximum usage of computers. 
Self-efficacy to Use Electronic Information Resources. A study on the Users of Research Institutes of Punjab

\section{Review of literature}

Young JuJoo (2000) observed that most research on WBI had been primarily descriptive in nature, with its emphasis on the technological aspects of classroom implementation. The study further examined effects of correspondence between self-efficacy beliefs and target performance on their predictive relations. Most hypotheses derived on the basis of the selfefficacy theory received support in the current WBI application. Abele, A. E. and Spurk, D. (2009) study uses self-efficacy, as a domain specific measure of computer anxiety due to its greater predictive power over general and task specific measures. Usher, E. L. and Pajares, F. (2009) conducted study in order to see how computer anxiety has an influence on employees' computer self-efficacy. Sources of computer self-efficacy were measured using a 24-item Sources of Computer Self-efficacy (SCSE) scale adapted from the 24-item Sources of Mathematics Scale. Guy, and Jackson (2010) study was also based on the self-efficacy believes measured by researchers at Historically Black College or University (HBCU) in the South. Study revealed that not all students are proficient with office applications. Mathew, D. (2012) studied that anxiety is a natural and unavoidable reaction to a perception of danger or risk. In her study, Gurpreet randhawa (2014) revealed that in determining the work performance level of employees, job specific self-efficacy plays a significant role. She also suggested that Employee's self-efficacy can be enhanced through counseling, proper guidance, training and development

\section{METHODOLOGY}

The main purpose of this study is to find out the need of self-efficacy to use Electronic Information Resources by users in the Libraries of Research Institutes of Punjab. This study adopted the survey approach to gather information on the use of EIRs. Questionnaire was used to collect the information.. The total no of 766 registered members of fifteen Research Institutes Libraries were selected for the study. These members have been grouped into three categories:

- Scientific staffs: include the Scientists and the Technicians.

- Research Scholars.

- Non - Scientific staffs: include staff working in Administration, Finance, Marketing, Doctors, etc.

\section{DATA ANALYSIS AND INTERPRETATION}

\section{Need of self-efficacy to use EIRs}

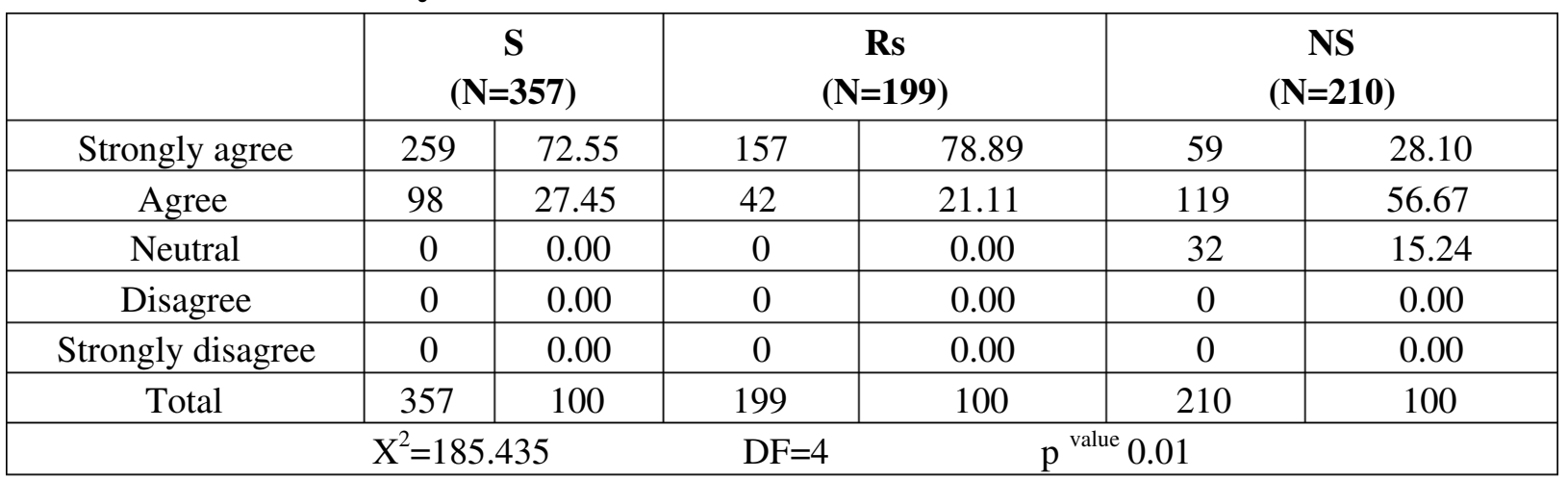

The table 1 indicates that all the scientific respondents [strongly agree (72.55\%); agree $(27.45 \%)$ ] and research scholars [strongly agree $(78.89 \%)$; agree $(21.11)$ ] agree and strongly agree that self-efficacy is necessary for using EIRs. On the other hand, around half $(56.67 \%)$ 
of the non-scientific respondents agree and one-fourth $(28.1 \%)$ strongly agree as to the need of self-efficacy for accessing EIRs. Whereas, 15.24 percent of the non-scientific respondents are neutral regarding the need of self-efficacy.

The chi square test was carried out to determine the association between respondents' opinion regarding the need for self-efficacy for accessing EIRs. $X^{2}=185.435$ with $p$ value 0.01 shows that there is a significant association between respondents' opinion regarding the need of self-efficacy for accessing and using EIRs.

\section{Use of EIRs between Scientific Respondents, Research Scholars and non- scientific respondents}

\begin{tabular}{|c|c|c|c|c|c|c|}
\hline List of EIRs & \multicolumn{2}{|c|}{ Scientific respondents } & \multicolumn{2}{c|}{ Research scholars } & \multicolumn{2}{c|}{ Non-scientific } \\
\hline EIRs & Mean & SD & Mean & SD & Mean & SD \\
\hline E-journals & 4.53 & 0.8 & 3.57 & 1.46 & 4.65 & 0.68 \\
\hline E-books & 4.39 & 0.85 & 3.29 & 1.59 & 4.33 & 0.77 \\
\hline Databases & 4.31 & 0.8 & 3.64 & 1.5 & 4.33 & 0.75 \\
\hline Blogs & 4.11 & 0.95 & 3.67 & 1.41 & 3.9 & 1.12 \\
\hline Internet & 4.81 & 0.55 & 4.62 & 0.69 & 4.84 & 0.52 \\
\hline OPAC & 3.83 & 1.1 & 2.73 & 1.64 & 4.12 & 1.16 \\
\hline Patents & 3.4 & 0.96 & 2.31 & 1.53 & 3.42 & 1.11 \\
\hline Standards & 3.07 & 0.95 & 2.37 & 1.44 & 3.15 & 1.11 \\
\hline Dictionaries & 4.51 & 0.82 & 4.1 & 1.04 & 4.51 & 0.87 \\
\hline $\begin{array}{c}\text { Online Theses } \\
\text { and Dissertations }\end{array}$ & 3.91 & 1.14 & 2.01 & 1.25 & 3.78 & 1.17 \\
\hline
\end{tabular}

Table 2 indicates that both scientific respondents and research scholars use all the EIRs to the level of score 4, except patents and standards. Few resources like internet and E-journals are used up to the level of 5 i.e. to the level of full extent. But in the case of non-scientific respondents, the use of EIRs is lesser than scientific respondents except for internet i.e. internet is used up to the level of 5.

An overall analysis makes it clear that the scientific respondents and research scholars are using more of each types of EIRs, than their non-scientific counterparts. This may be due to the fact that the information contained in these documents available in these libraries is more of scientific and technical value and it may be not useful for their professional work. Further, the lesser usage of patents and standards by both scientific respondents and research scholars could be the type of information contained in them, which either the scientific respondents or research scholars do not need regularly or frequently for their research and professional work. Thus, although the users (scientific respondents and research scholars) are aware of all the EIRs, the usage of them, depend on the information content of the EIRs and its need in their research or professional work.

\section{Ease of use of electronic information resources}

\begin{tabular}{|c|c|c|c|c|c|c|}
\hline \multirow{2}{*}{} & \multicolumn{2}{|c|}{ Scientific respondents } & \multicolumn{2}{c|}{ Research scholars } & \multicolumn{2}{c|}{ Non-scientific } \\
\cline { 2 - 7 }$(\mathbf{N}=\mathbf{3 5 7})$ & \multicolumn{2}{c|}{$\mathbf{( N = 1 9 9 )}$} & \multicolumn{2}{c|}{$\mathbf{( N = 2 1 0 )}$} \\
\hline very easy & 125 & 35.01 & 112 & 56.28 & 34 & 16.19 \\
\hline Easy & 75 & 21.01 & 55 & 27.64 & 41 & 19.52 \\
\hline To some extend & 87 & 24.37 & 32 & 16.08 & 54 & 25.71 \\
\hline Difficult & 70 & 19.61 & 0 & 0 & 81 & 38.57 \\
\hline Very difficult & 0 & 0 & 0 & 0 & 0 & 0 \\
\hline
\end{tabular}


Self-efficacy to Use Electronic Information Resources. A study on the Users of Research Institutes of Punjab

It is observed from the table 3 that more than three-fourths $(83.92 \%)$ of the research scholars [very easy (56.28) and easy (27.64)] and around half of the scientific respondents [very easy (35.01) and easy (21.01)] find the use of EIRs easy and very easy. It is also observed from the table that around one-fifth (19.61) of the scientific respondents find that EIRs are difficult to use. On the other hand, around one-third (35.71) of the non-scientific respondents opined that EIRs are easy (19.52\%) and very easy (16.19\%) to use. But 38.57 percent of the non-scientific respondents found out that EIRs are difficult to use.

\section{Problems they faced while using EIRs}

\begin{tabular}{|c|c|c|c|c|c|c|}
\hline \multirow{2}{*}{ Problems } & \multicolumn{2}{|c|}{$\begin{array}{c}\text { Scientific } \\
\text { respondents }\end{array}$} & \multicolumn{2}{c|}{ Research scholars } & \multicolumn{2}{c|}{ Non-scientific } \\
\cline { 2 - 7 } & \multicolumn{2}{|c|}{$\mathbf{( N = 3 5 7 )}$} & \multicolumn{2}{c|}{$\mathbf{( N = 1 9 9 )}$} & \multicolumn{2}{c|}{ (N=210) } \\
\hline Slow access speed & 255 & 71.43 & 153 & 76.88 & 174 & 82.86 \\
\hline Privacy & 87 & 24.37 & 20 & 10.05 & 47 & 22.38 \\
\hline Skills using EIRs & 21 & 5.88 & 17 & 8.54 & 150 & 71.43 \\
\hline Pay and access & 81 & 22.69 & 79 & 39.70 & 110 & 52.38 \\
\hline Information overloaded & 97 & 27.17 & 67 & 33.67 & 121 & 57.62 \\
\hline
\end{tabular}

The common problem faced by majority of the respondents from all the categories is the slow speed in accessing EIRs (scientific respondents 71.43\%; research scholars 82.86\%; nonscientific respondents $82.86 \%$ ). Nearly three-fourths of the non-scientific respondents (71.43\%) find the skills required for using EIRs to be a problem. Pay and access is another difficulty faced by half of the non-scientific respondents $(52.38 \%)$, around one-third of the research scholars $(39.70 \%)$ and one-fifth of the scientific respondents $(22.69 \%)$. It is also observed that information overload also poses difficulties in accessing EIRs (scientific respondents $27.17 \%$; research scholars $33.67 \%$; non-scientific respondents $57.62 \%$ ).

\section{FINDING OF THE STUDY}

This is clearly observed from the study that although the libraries of the Research Institutes, under study, have been providing different types of EIRs, the maximum used are the ones which are considered useful by the respondents. For ex. Internet, e-journals and Dictionaries in the case of Scientific respondents and Research Scholars and Internet in the case of nonscientific respondents. Apart from usage, as far as the computer - mediated resources are concerned, ease of use is equally important for using an EIR as has been stated by Mooer (1959), an information retrieval system will tend not to be used whenever it is more painful and troublesome for a customer to have information than for him not to have it. At this juncture, it is found from the study that around two-fifths of the non-scientific respondents and around one-fifth of the scientific respondents find the use of the EIRs difficult. When a user finds the use of technology difficult, it inhibits the use of the EIRs. Thus, apart from ease of use, confidence in the ability to use the technology, i.e. self-efficacy, is equally important. Belief in one's confidence and competency in using the technologies boosts the usage of the EIRs. Finding of the study brings forth many points of concern. Library should provide access to every type of resources i.e. general resources apart from the subject related materials. Library should organize training programme to overcome the anxiety of users. Furthermore, majority of users face slow internet access speed problems. Therefore there is a need to provide high bandwidth to overcome poor network connectivity. 


\section{REFERENCES:}

[1] Abele, A. E., and Spurk, D. 2009. The longitudinal impact of self-efficacy and career goals on objective and subjective career success. Journal of Vocational Behavior. 74(1):53-62 .

[2] Achim, A.N., and kassim,A.A. 2015. Computer usage: the impact of computer anxiety and computer self-efficacy. Procedia - Social and Behavioral Sciences 172 : $701-708$

[3] Bandura, A.1986. Self-Efficacy: Toward a Unifying Theory of Behavioral Change. Psychological Review84 (2):191-215.

[4] Compeau, D.R., and Higgins, C.A. 1995. Computer self-efficacy: development of a measure and initial test. MIS Quarterly 19:189-211.

[5] Gurjeet kaur. and Sami, Lalitha 2016. Users' behavior regarding Electronic Information Resources in the Library of NIPER Mohali. International journal for innovative research in multidisciplinary field 2(8):213-18.

[6] Kaur, Gurjeet. 2017. Electronic information resources in the libraries of research institutes of Punjab. A study of their users' attitude and satisfaction. phd diss., Gulbarga University Gulbarga, Karnataka, India .

[7] Guy, R. S., and Jackson, L. M. 2010. An Examination of Undergraduates' Self-Efficacy Beliefs and Demonstrated Computer Skills. Issues in Informing Science and Information Technology 7.

[8] Mathew, D. 2012. From fatigue to anxiety? Implications for educational design in a Web 2.0 world. Interactive Technology and Smart Education: 112-120.

[9] Saadé, R. G. and Kira, D. 2009. Computer anxiety in e-learning: the effect of computer self-efficacy. Journal of Information Technology Education 8:177-191.

[10] Sami, Lalitha and Gurjeet kaur. 2016. Awareness and use of electronic information resources in the research institute libraries of mohali, Punjab. Journal of Library, Information and Communication Technology (JLICT) 8 (1-2):1-7.

[11] Shu, Qin; Tu, Qiang; and Wang, Kanliang 2011. The Impact of computer self-efficacy and technology dependence on computer-related techno-stress: A Social cognitive theory perspective. Taylor \& Francis, Accessed from http://scholarworks.rit.edu/article/1293

[12] Usher, E. L. and Pajares, F. 2009. Sources of self-efficacy in mathematics: A Validation Study. Contempory Educational Psychology 34:89-101.

[13] Young, Ju, J.2000. Self-Efficacy for Self-Regulated Learning, Academic Self-Efficacy, and Internet Self-Efficacy in Web-Based Instruction. Educational Technology Research and Development, 48(2):5-17. 